\title{
Locoregional Transarterial Therapies for Hepatocellular Carcinoma: Transarterial Chemoembolization and Radioembolization
}

\author{
Mercedes Iñarrairaegui ${ }^{a, b}$ Delia D'Avola ${ }^{a, b} \quad$ Bruno Sangro ${ }^{a, b}$ \\ a Liver Unit, Clinica Universidad de Navarra, Pamplona, \\ ${ }^{\mathrm{b}}$ Centro de Investigacion Biomedica en Red de Enfermedades Hepaticas y Digestivas (CIBERehd), Barcelona, Spain
}

\section{Keywords}

Hepatocellular carcinoma, HCC · Chemoembolization ·

Radioembolization

\section{Summary}

Background: Hepatocellular carcinoma (HCC) is the sixth most common cancer in the world and the third most common cause of cancer-related mortality. Despite the widespread implementation of surveillance programs, more than half of the patients with HCC are diagnosed at late stages, when curative treatments (resection or liver transplantation) cannot be applied. For patients presenting with unresectable, non-transplantable HCC and a relatively preserved liver function, locoregional transarterial therapies are the main therapeutic options. Therefore, locoregional transarterial treatments play a key role in the management of HCC. The concept of catheter transarterial therapies is to selectively deliver anticancer treatments to liver tumors. This is possible due to the unique double irrigation of the liver and the predominantly arterial irrigation of liver tumors. Method: An exhaustive analysis of the literature, focused mainly on the last 25 years, has been carried out. Results: This review discusses the scientific evidence supporting the use of transarterial therapies for patients with HCC, including chemoembolization with conventional materials or drug-eluting beads, and internal radiation procedures such as the injection of radiation-loaded microspheres. Conclusion: Transarterial chemoembolization has been shown to improve the survival of those patients with unresectable HCC who have a preserved liver function and a low tumor burden. Recently developed devices and procedures, particularly drug-eluting beads and radioactive microspheres, may further improve the clinical outcome of patients receiving transarterial therapies. The combination with antiangiogenic agents is an appealing approach that should be explored.
Schlüsselwörter

Hepatozelluläres Karzinom, HCC · Chemoembolisation · Radioembolisation

\section{Zusammenfassung}

Hintergrund: Das Leberzellkarzinom (HCC) ist weltweit die sechsthäufigste Krebsart und die dritthäufigste Ursache von krebsbedingter Mortalität. Trotz der weit verbreiteten Anwendung von Überwachungsprogrammen befindet sich mehr als die Hälfte der Patienten mit HCC bei Diagnose bereits in einem späten Stadium, wenn kurative Behandlungen (Resektion oder Lebertransplantation) nicht angewendet werden können. Für Patienten mit inoperablem, nicht transplantierbarem $\mathrm{HCC}$ und relativ gut erhaltener Leberfunktion stellen lokoregionäre transarterielle Therapien die wichtigsten therapeutischen Optionen dar. Daher spielen lokoregionale transarterielle Behandlungen eine wichtige Rolle in der Handhabung des HCC. Das Konzept der transarteriellen Kathetertherapien besteht darin, Lebertumoren selektiv mit Anti-Krebs-Therapien zu behandeln. Dies ist aufgrund der einzigartigen doppelten Irrigation der Leber sowie der überwiegend arteriellen Irrigation von Lebertumoren möglich. Methode: Eine ausführliche Analyse der Literatur, die sich vor allem auf die letzten 25 Jahre konzentrierte, wurde durchgeführt. Ergebnisse: Diese Übersicht diskutiert die wissenschaftlichen Nachweise zur Verwendung von transarteriellen Therapien bei Patienten mit HCC, einschließlich Chemoembolisation mit konventionellen Materialien oder "drug-eluting beads", und internen Radiotherapien wie die Injektion von radioaktiven Mikrosphären. Schlussfolgerung: Für die transarterielle Chemoembolisation konnte gezeigt werden, dass das Überleben von Patienten mit inoperablem HCC, die eine erhaltene Leberfunktion und eine geringe Tumorlast aufweisen, verbessert wurde. Kürzlich entwickelte Geräte und Verfahren, insbesondere "drug-eluting beads" und radioaktive Mikrosphären, könnten das klinische Outcome der Patienten, die transarterielle Therapien erhalten, weiter verbessern. Die Kombination mit antiangiogenen Substanzen ist ein vielversprechender Ansatz, dem weiter nachgegangen werden sollte.

\section{KARGER \\ Fax +497614520714 \\ Information@Karger.com}

www.karger.com (c) 2013 S. Karger GmbH, Freiburg

1662-6664/13/0292-0092\$38.00/0

Accessible online at:

www.karger.com/vim 


\section{Introduction}

Hepatocellular carcinoma (HCC) is the sixth most common cancer in the world and the third most common cause of cancer-related mortality [1]. Cirrhotic patients are at a special risk of developing HCC, and this underlying liver disease impacts both on the therapeutic decision and the survival [2]. Early diagnosis of HCC can be achieved by surveillance of atrisk populations [3, 4]. Despite the widespread implementation of surveillance programs, more than half of the patients with HCC are diagnosed at late stages when curative treatments (resection or liver transplantation) cannot be applied [5]. For patients presenting with unresectable, non-transplantable HCC and a relatively preserved liver function, locoregional transarterial therapies are the main therapeutic options.

Locoregional transarterial therapies for unresectable HCC consist of a catheter-based group of treatments where therapeutic and/or embolic agents are intra-arterially directed to target tumors. The unique double irrigation of the liver and the predominantly arterial irrigation of liver tumors, particularly primary liver cancer, are at the core of all transarterial therapies. The most common techniques used in HCC treatment are transarterial chemoembolization (TACE) with or without drug-eluting beads (DEB) and Yttrium 90 (90Y) radioembolization (90Y-RE). TACE combines local and targeted drug delivery with concurrent tumor-feeding artery embolization. 90Y-RE is a form of brachytherapy in which intra-arterially injected microspheres loaded with $90 \mathrm{Y}$ serve as sources for internal radiation purposes.

This review focuses on these transarterial procedures and their role in the management of patients with HCC. It has to be stressed that the scientific evidence supporting the use of locoregional transarterial therapy is heterogeneous. The results of clinical trials aimed at investigating the benefit of transarterial therapies in different groups of patients as well as the synergies between locoregional and systemic therapies will be available in the coming years.

\section{Transarterial Chemoembolization}

TACE comprises a wide variety of procedures that share two different aims: i) to increase the exposure of tumor cells to chemotherapeutic agents; and ii) to induce ischemic necrosis. To achieve these two goals, TACE procedures involve the injection of chemotherapeutic agents usually followed by the injection of embolizing particles.

Several variations of this technique have been demonstrated throughout the world and no standard protocol has been uniformly adopted. Centers have differed in the choice and/or dose of the anticancer agents used, anticancer agent alone or mixed with lipiodol, the choice of the embolizing agent used, selectivity of catheter positioning, embolization endpoints, and the schedule and/or interval of retreatment [6]. This heterogeneity makes the analysis of the literature even more complicated.

Although conventional TACE with administration of an anticancer-in-lipiodol emulsion followed by embolic agents has been the most popular technique, bland embolization is still preferred in some centers, and TACE with drug-eluting particles (DEB-TACE) has replaced conventional regimens in others.

\section{Conventional Tace}

\section{Technical Considerations}

TACE is currently defined as the infusion of a mixture of chemotherapeutic agents with or without iodized oil, followed by an embolization with particles. In treating HCC, singleagent doxorubicin is commonly used, whereas the combination of mitomycin $\mathrm{C}$, doxorubicin, and cisplatin is preferred in the United States. Irrespective of the agent used, it is typically emulsified in lipiodol, an oily contrast agent believed to increase intratumoral retention of the cytotoxic agent. Iodized oil has been shown to act as a carrier of chemotherapeutic agents which are slowly released from the lipiodol mixture [7, 8]. The iodized oil persists selectively in the tumor for a few weeks or months because of hemodynamic differences between hypervascular hepatic tumors and liver parenchyma and presumably because of the absence of Kupffer cells in tumors [9]. This is followed by embolization of the target vessels with agents such as gelfoam (heterogeneous in size), the more recently calibrated polyvinyl alcohol, or acrylic copolymer gelatin particles [10]. The use of calibrated particles is increasing worldwide as they can be selected by size according to the vessel that needs to be blocked [11]. Vessel occlusion after injection of the chemotherapeutic mixture results in lower peak plasma concentration and increased drug retention inside the tumors [8]. Induced ischemic necrosis might result in the failure of transmembrane pumps in tumor cells, allowing a greater absorption of chemotherapeutic agents by the tumor [12].

However, the therapeutic benefit obtained from adding a chemotherapeutic agent or lipiodol to bland embolization was challenged by the results of two clinical trials conducted in the 1990s [13, 14]. Furthermore, two meta-analyses found similar outcomes after TACE or bland embolization $[6,15]$, suggesting that the antitumoral effect is mainly ischemic in nature. Nevertheless, in the following sections we will discuss only TACE as it is the most widely used transarterial embolizing procedure for HCC.

\section{Clinical Evidence}

The clinical evidence that supports the use of TACE for the palliative treatment of unresectable HCC comes from the positive results of two randomized controlled trials $[16,17]$ in 
Table 1. Median survival after $90 \mathrm{Y}-\mathrm{RE}$ and TACE (conventional and DEBTACE) according to tumor stage (BCLC)

\begin{tabular}{|c|c|c|c|c|c|}
\hline \multirow[t]{2}{*}{ BCLC } & \multirow[t]{2}{*}{ Author, year [reference] } & \multirow[t]{2}{*}{$\mathrm{N}$} & \multicolumn{3}{|c|}{ Median survival, months ( $95 \% \mathrm{CI})$} \\
\hline & & & 90Y-RE & cTACE & TACE-DCBeads \\
\hline \multirow[t]{9}{*}{ A } & Salem et al., 2010 [83] & 48 & $26.9(17.0-30.2)$ & - & - \\
\hline & Sangro et al., 2011 [85] & 52 & $24.4(18.6-38.1)$ & - & - \\
\hline & Salem et al., 2011 [35] & $43 / 47$ & $27.3(17.1-30.2)$ & $45.4(15.1-46.1)$ & - \\
\hline & Wang et al., 2008 [36] & 453 & - & 35.4 & - \\
\hline & Ho et al., 2009 [33] & 80 & - & 29.9 & - \\
\hline & Chen et al., 2009 [31] & n.r. & - & 16.8 & - \\
\hline & Lewandowski et al., 2010 [34] & 62 & - & $40(15-46)$ & - \\
\hline & Hsu et al., 2011 [32] & 73 & - & 37.9 & - \\
\hline & Burrel et al., 2012 [63] & 41 & - & - & $40.6(12.8-84.4)$ \\
\hline \multirow[t]{10}{*}{ B } & Salem et al., 2010 [83] & 83 & $17.2(13.5-29.6)$ & - & - \\
\hline & Hilgard et al., 2010 [84] & 51 & $16.4(12.1-\infty)$ & - & - \\
\hline & Sangro et al., 2011 [85] & 87 & $16.9(12.8-22.8)$ & - & - \\
\hline & Mazzaferro et al., 2013 [86] & 17 & $18(12-38)$ & - & - \\
\hline & Salem et al., 2011 [36] & $53 / 50$ & $17.2(11.4-29.6)$ & $17.2(14.8-18.7)$ & - \\
\hline & Wang et al., 2008 [37] & 741 & - & 18.2 & - \\
\hline & Chen et al., 2009 [31] & n.r. & - & 15.6 & - \\
\hline & Ho et al., 2009 [33] & 163 & - & 16.8 & - \\
\hline & Lewandowski et al., 2010 [34] & 73 & - & $17.4(13.9-18.8)$ & - \\
\hline & Burrel et al., 2012 [63] & 63 & - & - & $42.8(27.6-58.0)$ \\
\hline \multirow[t]{9}{*}{$\mathrm{C}$} & Salem et al., 2010 [83] & 107 no EHD & $7.3(6.5-10.1)$ & - & - \\
\hline & Salem et al., 2010 [83] & 45 EHD & $5.4(2.7-7.5)$ & - & - \\
\hline & Sangro et al., 2011 [85] & 183 & $10(7.7-10.9)$ & - & - \\
\hline & Mazzaferro et al., 2013 [86] & 35 & $13(9.0-17.0)$ & - & - \\
\hline & Salem et al., 2011 [36] & $13 / 12$ no PI & 22.1 (11.2-n.r.) & $9.3(6.2-11.5)$ & - \\
\hline & Lewandowski et al., 2010 [34] & 23 & - & $6.6(4.0-9.3)$ & - \\
\hline & Wang et al., 2008 [37] & 200 & - & 6.8 & - \\
\hline & Ho et al., 2009 [33] & 48 & - & 13.6 & - \\
\hline & Chen et al., 2009 [31] & n.r. & - & 12.7 & - \\
\hline
\end{tabular}

$\mathrm{EHD}=$ Extrahepatic disease; n.r. = not reported; $\mathrm{PI}=$ portal invasion.

selected patients with preserved liver function. Llovet et al. [16] prospectively studied the survival outcomes of patients treated with fixed interval (intention to treat) chemoembolization, embolization, and conservative measures. Survival outcomes showed a benefit in highly selected patients (younger than 75 years, free from main portal vein thrombosis (PVT), and preserved liver function) treated with chemoembolization and embolization versus those treated conservatively. The 2-year survival after conventional TACE reached $63 \%$ compared to $27 \%$ of the untreated control arm $(\mathrm{p}=0.009)$. In a second randomized controlled trial, Lo et al. [17] used broader enrollment criteria with the inclusion of patients with limited PVT resulting in a 2-year survival of only $31 \%$, although this outcome was still superior to that of the untreated control group (2-year survival 11\%; $\mathrm{p}=0.002$ ). Three other clinical trials failed to show the superiority of TACE in terms of survival compared to best supportive care or other not effective systemic treatments such as tamoxifen [18-20].

Unlike negative trials, the two trials with positive results recruited patients with slightly lower bilirubin levels, had a higher proportion of patients with one or two tumor nodules, and differed greatly in the etiology of HCC (mainly viral hepatitis in the two positive trials), while alcohol-related chronic liver disease was present in more than $70 \%$ of the patients in the negative trials.

However, three meta-analyses $[6,15,21]$ have concluded that TACE improves the survival of patients with unresectable HCC. Most patients included in the meta-analysis had a fully preserved liver function (normal median values for total bilirubin, serum albumin, or prothrombin time) and a rather small tumor burden (either single lesions or multiple tumors affecting a single lobe with a median tumor size of 5-7 $\mathrm{cm}$ and a small proportion of patients with elevated alpha-fetoprotein (AFP)).

Based on these results, TACE has been established as the standard of care for patients who meet the criteria for the intermediate stage of the Barcelona Clinic Liver Cancer (BCLC) staging system, i.e., those with multinodular HCC, relatively preserved liver function, absence of cancer-related symptoms, and no evidence of vascular invasion or extrahepatic spread $[2,22]$. 
However, in clinical practice, TACE has been applied to patients in other stages than the intermediate one; hence, survival is very heterogeneous and usually worse than that reported in clinical trials, as would be expected in a population that includes more diverse patients regarding liver function and tumor stage. Survival ranges widely in different series from 53 to $90 \%$ at 1 year, from 11 to $67 \%$ at 2 years, and from 8 to $26 \%$ at 5 years, reflecting the heterogeneous population treated [23-31]. According to the BCLC classification (table 1 ), reported survival ranges from 16 to 45 months in BCLC-A stage, from 15.6 to 18.2 months in BCLC-B stage, and between 6.8 and 13.6 in BCLC-C patients [31-36]. It has to be stressed that similar to other treatments, prognosis after chemoembolization largely depends on liver function [27, 29, 30, 37-39], tumor burden before treatment [23, 29, 30, 40], presence of portal vein invasion $[17,23,24,40,41]$, and response to treatment [16, 34].

In patients with portal vein invasion, the ischemic effect of TACE has precluded its use because of the risk of inducing liver failure. The extent of PVT that contraindicates TACE is still a matter of debate as patients with involvement of a segmental or lobar branch may achieve long-term outcomes that are much better than those expected from natural history, ranging from 5 to 10 months in some Eastern series with branch thrombosis $[42,43]$.

\section{Safety Profile}

TACE is generally considered a safe procedure. Nevertheless, it is frequently followed by side effects that can eventually be severe. The most common is the postembolization syndrome, consisting of nausea, abdominal pain, and fever. It occurs in more than $40 \%$ of patients $[44,45]$ but is commonly mild and transient. A variable proportion of patients $(20$ $45 \%$ ) show a transient deterioration of varying degree in liver function after TACE [44, 46], and some series report acute liver decompensation (appearance of ascites, encephalopathy, or jaundice) in $0.1-3 \%$ of the cases $[18,45,47,48]$. In some series, biliary and gastrointestinal tract injury has been reported in $2-10 \%$ [49-51] and in $1-5 \%$ of the patients [45, 52], respectively. Mortality rates range widely from 0.003 to $10 \%$ in the different series $[15,23,53]$, reflecting again the heterogeneity in the treatment population as well as the type of regimen and the frequency of the treatment.

Liver functional reserve is a critical component of a careful selection. Patients should present a relatively well-preserved liver function (mostly Child-Pugh A or B7 without ascites), while those with liver decompensation or more advanced liver failure should be excluded since the ischemic insult can lead to severe adverse events. A recent consensus from a panel of experts has recommended a series of absolute and relative contraindications for the treatment of patients at BCLC-B stage, which also applies to the BCLC-C stage since the contraindication for the treatment of PVT is not universally accepted [54].

\section{TACE Using DEB}

\section{Technical Considerations}

The concept of DEB-TACE is to load embolizing particles with various types of chemotherapeutic agents and to deliver them intra-arterially in a manner similar to that of conventional TACE. These beads are able to take up several drugs by ion exchange in vitro in a fixed dosing and to release them in vivo in a sustained fashion after intra-arterial injection. DEB are composed of either a sulfonate-modified poly(vinyl alcohol) hydrogel (DC Bead ${ }^{\circledR}$; Biocompatibles, Surrey, UK) or a sodium acrylate and vinyl alcohol copolymer (HepaSphere ${ }^{\mathrm{TM}}$; BioSphere Medical, Inc., Rockland, MA, USA). For the treatment of HCC, both particles can be loaded with doxorubicin. Significant reductions of peak plasma concentrations have been observed with DEB when compared with conventional chemoembolization, suggesting that a greater amount of the anticancer agent is being sequestered by the tumor versus being released in the systemic circulation [55]. With regard to their embolizing properties, DEB tend to produce a more distal occlusion than polyvinyl alcohol particles, and the rate of recanalization is considerably lower [11].

\section{Clinical Evidence and Safety Profile}

The first human reports on TACE with DEB in HCC [56, 57] supported the preclinical investigation and the results achieved in animal models, administering doses of up to 150 $\mathrm{mg}$ doxorubicin without relevant drug-related toxicity, consistent with reduced systemic exposure to the drug. Consistent objective response at a rate of $60-66.6 \%$ using the European Association for the Study of the Liver (EASL) criteria [57, 58] and of $70 \%$ according to mRECIST were reported [56].

Postembolization syndrome was observed in 41 and $18 \%$ of the treated patients after the first and the second treatment, respectively. There were two cases of liver abscesses in the series from Varela [57], and the treatment-related complication rate was $11 \%$ in the phase I-II study [56].

In a large, international randomized controlled trial comparing conventional TACE with DEB-TACE using DC Beads, primary endpoints (superiority of DEB-TACE in achieving objective tumor response at 6 months according to EASL criteria and in producing fewer treatment-related serious adverse events in the first 30 days) were not met. Tumor response rates were 52 and $44 \%$ and time to progression (TTP) was 7.1 and 6.4 months for DEB-TACE and conventional TACE, respectively. However, DEB-TACE produced a significantly higher response rate in a small subgroup of patients carrying the worst prognosis (e.g., those with ChildPugh B, Eastern Cooperative Group Oncology (ECOG) 1, bilobar disease, and recurrent disease) and was associated with a significant reduction of doxorubicin-related side effects [59]. This potential advantage should be treated with caution as it comes from the analysis of a very small group of patients and as it is generally recognized that TACE should be indi- 
cated very stringently in this subgroup of patients who have a poor prognosis for which a survival advantage has not been shown after conventional TACE. Regarding the use of HepaSphere, few data on HCC patients are available but a similar response rate of $51 \%$ at 6 months was reported in a multicenter study [60].

Malagari et al. [61] have reported on 173 patients prospectively enrolled and treated segmentally with DEB-TACE. All patients had underlying cirrhosis (Child-Pugh class A or B) and were in BCLC stages A (22\%) and B (78\%). The overall survival rate at 1,3 , and 5 years was $93.6,62$, and $22.5 \%$. The majority of patients $(74 \%)$ were observed to have varying degrees of self-limiting postembolization symptoms. Major complications occurred in $4.1 \%$ of the patients and included liver abscess, cholecystitis, pleural effusion, and three cases of irreversible liver failure [61].

The same authors conducted a prospective randomized comparison of DEB-TACE and bland embolization in 84 cirrhotic patients. The objective response rate according to EASL criteria was higher in the DEB-TACE group than in the bland embolization group at 9 months (55 vs. $31 \%$ ). However, the survival rate at 12 months was similar in both groups (85.3\% for the DEB-TACE group and $86 \%$ for the bland embolization group) [62].

The most recent data published to date comes from the Barcelona retrospective series [63]. A total of 104 well-compensated cirrhotic patients (95\% with Child-Pugh A) were treated with DEB-TACE. After censoring for other treatments, the median overall survival was 40.6 months (95\% confidence interval (CI): 12.8-84.4) in BCLC-A stage (40\% of the patients) and 42.8 months (95\% CI: 27.6-58.0) for BCLCB stage ( $60 \%$ of the patients). However, the median follow-up was 24.5 months and therefore much shorter than the median survival, so this result warrants prolonged follow-up to be confirmed. In order to offer a larger standardization procedure, treatment frequency and schedule should be detailed. Major complications developed in $10 \%$ of the patients, and single treatment-related death was at $0.96 \%$.

\section{Combination with Systemic Agents}

TACE potentially causes hypoxia in tumors as well as in surrounding liver tissues due to the anticancer effects of chemotherapy and embolization to feeding arteries. Ischemic injury after TACE can induce upregulation of circulating vascular endothelial growth factor (VEGF) [64], which is essential for HCC growth, invasion, and metastasis. Recent studies have reported a significant association between VEGF upregulation after TACE and poor prognosis $[65,66]$. Therefore, adjuvant or concurrent use of an antiangiogenic agent may be helpful for HCC patients who are treated with TACE. TACE plus an antiangiogenic agent, such as sorafenib, could potentially provide complementary inhibition of angiogenic factors and tumor growth [67]. Combination strategies that have been proposed [67] include: i) a sequential schedule in which systemic therapy is started after all TACE sessions are completed, with an adjuvant intention to delay or block the growth of metastasis; ii) a continuous schedule in which systemic therapy is started before the first TACE session and maintained thereafter to provide better interference with the peak production of neoangiogenic factors after each session; and iii) an interrupted schedule in which systemic therapy is put on hold for a few days after each TACE session to reduce the chance of synergistic toxicity.

Several clinical trials are currently evaluating the effect of conventional TACE or DEB-TACE with systemic agents on the outcome of patients with unresectable HCC, using all three schedules [68]. The results of three of these randomized controlled trials are already available. Kudo et al. [69] failed to show an improvement in TTP among patients with unresectable HCC in Child-Pugh A stage with $>25 \%$ tumor necrosis or shrinkage at 1-3 months following one or two TACE sessions that received sorafenib when compared to those that received placebo (5.4 vs. 3.7 months; $\mathrm{p}=0.25$ ). Overall survival was not significantly different between groups. The two other phase II trials were aimed to assess the safety of the combination of sorafenib with conventional TACE [70] or with DEB-TACE [71]. Both trials showed a safe profile, with most adverse events being related to sorafenib and manageable with dose modifications. Preliminary data from the SPACE study (NCT 00494299) were presented at the American Society of Clinical Oncology [72]. This phase II study explored the combination of a continuous regimen of sorafenib with DEB-TACE versus DEB-TACE alone, with TTP as primary endpoint. The hazard ratio for TTP was 0.797 (95\% CI: $0.588-1.080 ; \mathrm{p}=0.072$ ). Although this preliminary efficacy data are encouraging, definitive results of ongoing, large phase III trials (ECOG study - NCT 01004978) are needed to confirm these results.

\section{Radioembolization}

\section{Technical Considerations}

The term radioembolization (90Y-RE) was proposed by a group of experts to define those procedures in which intra-arterially injected radioactive microspheres are used for internal radiation treatment (mainly in the liver) [73]. The term selective internal radiation therapy (SIRT) has been widely used to name these procedures but it may be confusing since nontransarterial techniques such as high-dose-rate interstitial brachytherapy also provide selective internal radiation.

There are different radioactive isotopes used for the treatment of liver tumors; however, $90 \mathrm{Y}$ is the one most commonly utilized due to its specific properties as a pure beta emitter, with a half-life of $64.2 \mathrm{~h}$ and a short tissue penetration (mean: 
$2.5 \mathrm{~mm}$ ). Consequently, isolation for radiation protection is not needed following treatment. There are two types of commercially available radioactive microspheres: $90 \mathrm{Y}$ glass microspheres (TheraSphere ${ }^{\circledR}$; MDS Nordion, Ottawa, ON, Canada) and 90Y resin microspheres (SIR-Spheres ${ }^{\circledR}$; Sirtex Medical Limited, Sydney, Australia). Beyond the differences in the materials used for each type of microspheres, these devices differ in the amount of radioactive isotope loaded in each microsphere (larger for glass microspheres), which in turn determines the number of microspheres typically injected in a single treatment (smaller for glass microspheres).

In TACE, particles larger than 100 microns are used to occlude tumor-feeding vessels in order to produce ischemia and to increase the drug exposure of tumor cells. 90Y-RE does not produce an occlusion of large- or medium-sized arteries, and the smaller particles used in radioembolization (20-60 $\mathrm{mm}$ ) reach the tumor microvasculature, and therefore, high doses of radiation are delivered preferentially to tumor tissues. The efficacy and toxicity of the treatment are thus a consequence of radiation and to some extent of microembolization, but are not due to ischemia.

A simulation of the actual treatment is performed 1-2 weeks prior to radioembolization. It consists of a thorough angiographic evaluation to detect extrahepatic vessels irrigating liver tumors as well as to detect, and to eventually occlude, aberrant vessels arising from hepatic arteries that may feed the gastrointestinal tract (mainly gastroduodenal artery and right gastric artery). During this arteriography, technetium99m-labeled macroaggregated albumin (99mTc-MAA) is injected as a tracer. 99mTc-MAA allows for planar and/or SPECT gamma-camera imaging, which can be used to measure hepatopulmonary shunting and to anticipate an average dose of radiation that could be delivered to tumor areas. $\mathrm{Pa}$ tients can only be considered for 90Y-RE provided that the degree of arteriovenous shunting to the lung is limited, that there is no possibility of microspheres potentially reaching the gastrointestinal tract, and that the liver has had no prior exposure to external irradiation [73]. Liver function must be adequate, without ascites or hepatic encephalopathy, and with a total bilirubin $<2 \mathrm{mg} / \mathrm{dl}$ [74].

\section{Clinical Evidence}

All the evidence comes from retrospective series or noncontrolled prospective studies [41, 75-82] without any randomized controlled trials comparing 90Y-RE with other available therapies. However, in the last 3 years four large series have provided valuable information for the different stages of HCC and may allow putting the outcomes in the perspective of other treatments, mainly in terms of survival [82-86]. Besides, some of these series provide data on toxicity and on surrogate endpoints that are likely to predict clinical benefit, such as objective tumor response rates and TTP. Despite this growing body of evidence and due to the lack of randomized controlled trials, $90 \mathrm{Y}-\mathrm{RE}$ is not recommended in the proposed algorithms of treatment in the EASL and AASLD (American Association for the Study of Liver Diseases) guidelines [2, 22]. However, its use is considered in other guidelines such as those by the European Society for Medical Oncology (ESMO) [87] and the National Comprehensive Cancer Network (NCCN) [88].

First reports in the literature mainly included the application of $90 \mathrm{Y}-\mathrm{RE}$ for the treatment of unresectable advanced HCC. In the last years, as its use has been extended, some series have reported the outcomes of $90 \mathrm{Y}$-RE in early tumors.

90Y-RE can induce complete necrosis in targeted lesions, as has been suggested by the analyses of 35 explanted livers from patients treated with 90Y-RE, as a bridge or after successful downstaging to liver transplantation. Nearly $90 \%$ of the tumors up to $3 \mathrm{~cm}$ in size and two-thirds of those between 3 and $5 \mathrm{~cm}$ had a complete pathologic necrosis [89].

In terms of survival, recent series describing outcomes according to tumor stage have reported a consistent median overall survival of around 26 months $[35,83,84]$ in patients at early stages (inoperable BCLC-A) after 90Y-RE. This survival is in between the wide range of median survival from 16.8 to 45.4 months reported with TACE/transarterial embolization (TAE) in large series of BCLC-A patients, as previously described [31-36, 63]. Median TTP in this early stage has been described as long as 25.1 months (95\% CI: 8-27 months), i.e., longer than the one observed with TACE in a retrospective, well-balanced comparative study between both techniques (TACE and 90Y-RE) [35], and this may provide a rationale for its use as a bridge to liver transplantation in an attempt to avoid dropping from the waiting list [90].

The potential to induce intense tumor responses has allowed 90Y-RE to be used as a downstaging therapy, to reduce the tumor burden within acceptable limits for liver transplantation, to render non-operable patients operable, or to simplify surgery. Besides tumor response, atrophy of the radiated lobe after 90Y-RE and contralateral lobe hypertrophy as a result of the injection of a high-activity $90 \mathrm{Y}$ in a lobar hepatic artery, known as 'radiation lobectomy', may contribute to resectability [91]. In the largest series published with $90 \mathrm{Y}$ glass microspheres for downstaging HCC to radical therapies, 23 of 35 patients $(66 \%)$ achieved resection, radiofrequency ablation (RFA), T2 status, or transplant, although 8 of these patients (23\%) chose close observation rather than RFA or transplantation, and the 1- and 3-year survival rates achieved were 84 and $27 \%$, respectively [69]. Compared with TACE, downstaging from $\mathrm{T} 3$ to $\mathrm{T} 2$ was achieved more frequently with $90 \mathrm{Y}-\mathrm{RE}$ ( 58 vs. $31 \% ; \mathrm{p}=0.023$ ), and overall survival was in favor of 90Y-RE (censored: 35.7 vs. 18.7 months for TACE, $\mathrm{p}=0.18$; uncensored: 41.6 vs. 19.2 months, $\mathrm{p}=0.008$, respectively) [80]. Our group has also analyzed the potential of downstaging HCC with $90 \mathrm{Y}$ resin microspheres in patients in T3 stage treated for palliative intent. Overall, $29 \%$ of 21 UNOS 
Table 2. Median survival according to the presence or absence of portal vein thrombosis (PVT) and extrahepatic disease (EHD) with ${ }^{90} \mathrm{Y}-\mathrm{RE}$ and conventional TACE

\begin{tabular}{|c|c|c|c|c|c|}
\hline & \multirow[t]{3}{*}{ Author, year [reference] } & \multicolumn{4}{|l|}{ PVT } \\
\hline & & \multicolumn{2}{|l|}{ yes } & \multicolumn{2}{|l|}{ no } \\
\hline & & number of patients & $\begin{array}{l}\text { median survival, } \\
\text { months }(95 \% \mathrm{CI})\end{array}$ & number of patients & $\begin{array}{l}\text { median survival, } \\
\text { months }(95 \% \mathrm{CI})\end{array}$ \\
\hline \multirow[t]{7}{*}{${ }^{90} \mathrm{Y}-\mathrm{RE}$} & \multirow[t]{2}{*}{ Kulik et al., 2008 [80] } & 12 main PVT & $4.4(2.9-7.5)$ & \multirow[t]{3}{*}{71} & \multirow[t]{3}{*}{$15.5(10.7-20.9)$} \\
\hline & & 25 branch PVT & $10.1(7.2-16)$ & & \\
\hline & Iñarrairaegui et al., 2010 [81] & 25 (72\% branch PVT) & $10(6.6-13.3)$ & & \\
\hline & Hilgard et al., 2010 [84] & 33 (50\% branch PVT) & $10(6-\infty)$ & 75 & $16.4(12.1-\infty)$ \\
\hline & Woodall et al., 2009 [101] & 15 (73\% main PVT) & 3.2 & 20 & 13.9 \\
\hline & Sangro et al., 2011 [84] & $76(58 \%$ branch PVT) & $10.0(6.5-11.8)$ & 249 & $15.3(12.4-18.4)$ \\
\hline & Mazzaferro et al., 2013 [86] & $\begin{array}{l}29 \text { branch or segmental PVT } \\
6 \text { main PVT }\end{array}$ & $\begin{array}{c}14(11-18) \\
8(5-8)\end{array}$ & \multirow[t]{3}{*}{17} & $18(12.0-38.0)$ \\
\hline \multirow[t]{5}{*}{ TACE } & \multirow[t]{5}{*}{ Luo et al., 2011 [42] } & 44 main PVT & 5.3 & & \\
\hline & & 40 branch PVT & 10.2 & & \\
\hline & & \multicolumn{4}{|l|}{ EHD } \\
\hline & & \multicolumn{2}{|l|}{ yes } & \multicolumn{2}{|l|}{ no } \\
\hline & & number of patients & $\begin{array}{l}\text { median survival, } \\
\text { months }(95 \% \mathrm{CI})\end{array}$ & number of patients & $\begin{array}{l}\text { median survival, } \\
\text { months }(95 \% \mathrm{CI})\end{array}$ \\
\hline \multirow[t]{2}{*}{${ }^{90} \mathrm{Y}-\mathrm{RE}$} & Sangro et al., 2011 [85] & 30 & $7.4(4.8-13-1)$ & 295 & $14.1(11.7-16.8)$ \\
\hline & Salem et al., 2011 [35] & 45 & $5.4(2.7-7.5)$ & 107 (BCLC-C) & $7.3(6.5-10.1)$ \\
\hline
\end{tabular}

(United Network for Organ Sharing) T3 stage patients were downstaged and underwent surgical resection or liver transplantation, with a 3-year survival rate of $75 \%$ [92], which is comparable with the survival of patients with early-stage disease who are treated radically at the time of diagnosis.

BCLC stage B patients treated with $90 \mathrm{Y}-\mathrm{RE}$ have reached a median survival ranging between 16.4 and 18 months [83, 85, 86], comparable with the median survival achieved by TACE in this stage (15.6-18.2 months) [31-34, 36]. These findings are confirmed by retrospective analyses of different stages of HCC treated with TACE or 90Y-RE at the same institution in which nearly equivalent survivals between these treatments were found [35, 93-95]. Salem et al. [35] have reported the compared outcomes of patients that did not show PVT or extrahepatic disease. This series mainly included patients with intermediate $(53 \%)$ or early $(35 \%)$ tumors treated in the same period (2001-2010) in which treatment allocation was decided by a multidisciplinary team. When patients in the intermediate stage were evaluated separately, an identical survival rate in the intermediate stage was observed after each treatment (15.5 vs. 17.2 months).

Besides, not all patients with intermediate-stage HCC are considered good candidates for TACE as those patients with a bulky disease or one affecting both lobes are widely regarded as poor candidates [54]. In this subgroup of intermediate patients, 90Y-RE can improve survival compared with either experimental therapies or best supportive care (16 vs. 8 months; $p<0.05$ ), as shown by a case-control study [96], and is similar to the me- dian survival of 14.5 months achieved in the sorafenib arm of BCLC stage B patients of the SHARP (Sorafenib HCC Assessment Randomized Protocol) trial [97]. For patients who fail to respond to TACE, the only remaining treatment options are either sorafenib or 90Y-RE. In a subset analysis of SHARP studies, survival in patients failing TACE was 11.9 and 9.9 months for the sorafenib and the placebo treatment arms, respectively [97]. By comparison, investigators from the European Network on Radioembolization with $90 \mathrm{Y}$ resin microspheres (ENRY) found that survival was 11.4 months for a subset of usual candidates for 90Y-RE (matching the SHARP criteria) and 15.4 months in BCLC-B patients failing TACE/TAE [85].

Sorafenib is the mainstay for treating advanced HCC, defined by the presence of vascular invasion, extrahepatic disease, or deteriorated performance status in a patient with at least partially preserved liver function. As 90Y-RE has no macroembolic effect $[98,99]$, it can be successfully applied to patients with PVT and can offer a similar median survival in the range of 6 to 13 months [83-86], being very akin to the 6.5-10.7 months reported in the phase III clinical trials of sorafenib in the same group of patients $[100,101]$. However, one must take into account that the extent of PVT also matters. When thrombosis affects the main trunk, survival is more disappointing and ranges between 3.2 and 8 months [80, 86, 102], while survival extends to $10-14$ months in patients with branch thrombosis only (table 2) [80, 81, 86].

Metastases are not the direct cause of death in the majority of HCC patients; thus, a locoregional treatment may be 
considered when a small metastatic burden involves non-vital organs such as bone, adrenal glands, or lymph nodes. Nevertheless, extrahepatic disease is an indicator of disease aggressiveness [102], and median survival in metastatic patients treated with $90 \mathrm{Y}-\mathrm{RE}$ is poor, ranging between 5.4 and 7.4 months $[83,85]$.

\section{Safety Profile}

The toxicity profile of $90 \mathrm{Y}-\mathrm{RE}$ is favorable and treatment is generally well tolerated. A postembolization syndrome like the one that appears after TACE is not seen; however, in large series several rather mild procedure-related symptoms, including fatigue (54-61\%), abdominal pain (23-56\%), nausea and vomiting (20-32\%), and low-grade fever (3-12\%), may ensue that usually last only a few hours [83-86]. Potentially more serious adverse events resulting from irradiation of non-tumoral tissues include pneumonitis [103], cholecystitis [104], gastrointestinal ulceration [105], and liver damage, but these events are uncommon.

Liver toxicity after $90 \mathrm{Y}-\mathrm{RE}$ is the most challenging adverse event in HCC patients as the majority of these tumors arise in cirrhotic livers, with some degree of reduced functional reserve. However, it is sometimes difficult to differentiate between the liver damage due to the treatment with 90Y-RE and the deterioration of liver function as a consequence of disease progression of the liver disease. A comprehensive analysis of the data in the literature is hampered by the wide variations between the patient series in the timing of liver function testing after $90 \mathrm{Y}-\mathrm{RE}$, in the populations treated, and in the toxicity criteria used. Hyperbilirubinemia has been reported in 3-40\% [76, 77, 80, 84, 101, 104], while hypertransaminasemia or elevation of cholestasis enzymes has been described between 0 and $80 \%$ [76, 77, 84, 85, 104, 106]. Signs of liver dysfunction, such as ascites (0-18\%) or encephalopathy (0-4\%), also vary between series [76, 77, 80, 84, 101, 104]. The only group that has published specific liver toxicity induced by 90Y-RE has described in non-cirrhotic livers a clinical syndrome characterized by jaundice, mild ascites, and a moderate increase in GGT and alkaline phosphatase, histopathologically similar to a sinusoidal obstruction syndrome, which is called radioembolization-induced liver disease (REILD) [107]. Its incidence in cirrhotic patients was $9.3 \%$ in the largest series reported so far [108].

Safety is a special issue in patients with compromised liver flow, similar to those with PVT. In the first and largest series published by the Chicago group, patients with cirrhosis and PVT involving the main trunk had a higher incidence of adverse events (a non-statistically significant increment in bilirubin levels and a significant increase in ascites) [80]. The ENRY series analyzed main clinical adverse events and liver toxicity in the different BCLC stages and observed similar liver toxicity across BCLC stages A through C [85]. Com- pared to those with intermediate or early stage disease, only fatigue was most commonly reported in the advanced stage $(61.2 \%)$, which is not surprising since fatigue is usually associated with altered performance status. Finally, no significant differences in toxicity were registered when patients with and without PVT were compared in the Milan phase II trial [86].

Despite an intense local effect of 90Y-RE on target lesions, progression is usually the result of the growth of new liver lesions, particularly in those patients with more advanced disease. New lesions arise as frequently in the targeted areas as in the non-targeted areas of the liver, reflecting the irrelevant therapeutic effect of Y90-RE on HCC micrometastases, probably due to their poor arterial blood supply. And importantly, the early appearance of new lesions has prognostic relevance since these patients have a much worse prognosis.

The combination of systemic therapy with sorafenib and 90Y-RE is being investigated in two trials, i.e. SORAMIC (NCT 01126645) and STOP-HCC (NCT 01556490), with survival as primary endpoint in non-resectable HCC patients. Finally, two head-to-head comparisons of sorafenib versus $90 \mathrm{Y}$ $\mathrm{RE}$ with survival as the primary endpoint are now ongoing (SIRveNIB - NCT 01135056; SARAH - NCT 01482442).

\section{Conclusion}

TACE is in fact a very heterogeneous group of procedures that is actually performed in very different ways regarding materials, extent and selectivity of vessel occlusion, and timing of repeated sessions. Good results are generally observed when a reduced number of not very large tumors are embolized in a selective fashion (ideally through a distinct feeding vessel). In the past few years, DEB-TACE has become a reproducible and well-tolerated procedure associated with low complication as well as promising tumor response rates and is a valuable alternative to conventional TACE in some centers. However, all clinical trials conducted so far have failed to show an advantage of DEB-TACE over conventional TACE regarding response rate or overall survival. Secondary endpoints including reduction of drug-related adverse events or increased intratumoral necrosis (which makes the difference between RECIST and EASL criteria) have been successfully proven and are consistent with the well-known characteristics of the beads as shown in preclinical work.

Y90-RE is a form of brachytherapy for liver tumors in which the source of radiation has to access the network of tumoral neovessels after having been injected into the hepatic arteries. Evidence supporting the usefulness of 90Y-RE in the treatment of HCC patients is derived from non-controlled series. Most information comes from patients with advanced $\mathrm{HCC}$ who are not suitable for other locoregional therapies or who have failed in TACE. In recent years, however, encouraging experience has been reported in the treatment of HCC patients at earlier stages, including those in 
which downstaging is likely to be beneficial. There is a group of patients for which the benefit of being treated with $90 \mathrm{Y}$ RE is unlikely or needs to be further substantiated. This group includes patients with diffuse bulky disease involving more than $50 \%$ of liver volume as well as patients with a tumoral thrombosis of the main portal trunk and a poor liver functional reserve.

Due to the lack of randomized controlled trials comparing both techniques, it is a difficult question to answer how Y90RE does compare to TACE in the same patient population. For those patients with small- to medium-sized tumors that can be treated selectively, TACE is certainly the standard of care and can be provided in most centers. Y90-RE could then be an alternative to repeated TACE for patients who fail to respond to initial TACE and a first option for those who are poor candidates for TACE, mainly because of bulky disease and PVT, but who still have a good liver function.

In the next years, much attention is likely to be paid to the combination of targeted agents with antiangiogenic activity and locoregional therapies. The results of the ongoing clinical trials will establish the best way of combining sorafenib and other targeted therapies with locoregional procedures, including TACE and Y90-RE.

\section{Disclosure Statement}

Mercedes Iñarrairaegui and Delia D'Avola do not have any financial disclosures. Bruno Sangro receives lecture fees from Sirtex Medical Europe $\mathrm{GmBH}$ and Bayer Health Care.

\section{References}

1 Bosch FX, Ribes J, Diaz M, et al: Primary liver cancer: worldwide incidence and trends. Gastroenterology 2004;127:S5-S16.

2 European Association For The Study Of The Liver; European Organisation For Research And Treatment Of Cancer: EASL-EORTC clinica practice guidelines: management of hepatocellular carcinoma. J Hepatol 2012;56:908-943.

3 Bolondi L, Sofia S, Siringo S, et al: Surveillance programme of cirrhotic patients for early diagnosis and treatment of hepatocellular carcinoma: a costeffectiveness analysis. Gut 2001;48:251-259.

4 Sangiovanni A, Del Ninno E, Fasani P, et al: Increased survival of cirrhotic patients with a hepatocellular carcinoma detected during surveillance. Gastroenterology 2004;126:1005-1014.

5 Kim WR, Gores GJ, Benson JT, et al: Mortality and hospital utilization for hepatocellular carcinoma in the United States. Gastroenterology 2005; 129:486-493.

6 Marelli L, Stigliano R, Triantos C, et al: Transarterial therapy for hepatocellular carcinoma: which technique is more effective? A systematic review of cohort and randomized studies. Cardiovasc Intervent Radiol 2007;30:6-25.

7 Nakamura H, Hashimoto T, Oi H, et al: Transcatheter oily chemoembolization of hepatocellular carcinoma. Radiology 1989;170:783-786.

8 Raoul JL, Heresbach D, Bretagne JF, et al: Chemoembolization of hepatocellular carcinomas. A study of the biodistribution and pharmacokinetics of doxorubicin. Cancer 1992;70:585-590.

9 Kan Z, McCuskey PA, Wright KC, et al: Role of Kupffer cells in iodized oil embolization. Invest Radiol 1994;29:990-993.

10 Coldwell DM, Stokes KR, Yakes WF: Embolotherapy: agents, clinical applications, and techniques. Radiographics 1994;14:623-643.

11 Bilbao JI, de Luis E, Garcia de Jalon JA, et al: Comparative study of four different spherical embolic particles in an animal model: a morphologic and histologic evaluation. J Vasc Interv Radiol 2008;12:1625-1638.

12 Kruskal JB, Hlatky L, Hahnfeldt P, et al: In vivo and in vitro analysis of the effectiveness of doxorubicin combined with temporary arterial occlusion in liver tumors. J Vasc Interv Radiol 1993;4: 741-747.
13 Chang JM, Tzeng WS, Pan HB, et al: Transcatheter arterial embolization with or without cisplatin treatment of hepatocellular carcinoma. A randomized controlled study. Cancer 1994;74:2449-2453.

14 Kawai S, Okamura J, Ogawa M, et al: Prospective and randomized clinical trial for the treatment of hepatocellular carcinoma - a comparison of lipiodol-transcatheter arterial embolization with and without adriamycin (first cooperative study). The cooperative study group for liver cancer treatment of Japan. Cancer Chemother Pharmacol 1992;31 (suppl):S1-6.

15 Cammà $\mathrm{C}$, Schepis $\mathrm{F}$, Orlando $\mathrm{A}$, et al: Transarterial chemoembolization for unresectable hepatocellular carcinoma: meta-analysis of randomized controlled trials. Radiology 2002;224:47-54.

16 Llovet JM, Real MI, Montaña X, et al: Arterial embolisation or chemoembolisation versus symptomatic treatment in patients with unresectable hepatocellular carcinoma: a randomized controlled trial. Lancet 2002;359:1734-1739.

17 Lo CM, Ngan H, Tso WK, et al: Randomized controlled trial of transarterial lipiodol chemoembolization for unresectable hepatocellular carcinoma. Hepatology 2002;35:1164-1171.

18 A comparison of lipiodol chemoembolization and conservative treatment for unresectable hepatocellular carcinoma. Groupe d'etude et de traitement du carcinoma hepatocellulaire. N Engl J Med 1995; 332:1256-1261.

19 Pelletier G, Ducreux M, Gay F, et al: Treatment of unresectable hepatocellular carcinoma with lipiodol chemoembolization: a multicenter randomized trial. Groupe CHC. J Hepatol 1998;29:129-134.

20 Doffoel M, Bonnetain F, Bouche O, et al: Multicentre randomised phase III trial comparing tamoxifen alone or with transarterial lipiodol chemoembolization for unresectable hepatocellular carcinoma in cirrhotic patients (federation francophone de cancerologie digestive 9402). Eur J Cancer 2008;44:528-538.

21 Llovet J, Bruix J: Systematic review of randomized trials for unresectable hepatocellular carcinoma: chemoembolization improves survival. Hepatology 2003;37:429-442.

22 Bruix J, Sherman M: Management of hepatocellular carcinoma: an update. Hepatology 2011;53: 1020-1022.
23 Takayasu K, Arii S, Ikai I, et al: Prospective cohort study of transarterial chemoembolization for unresectable hepatocellular carcinoma in 8510 patients. Gastroenterology 2006;131:461-469.

24 Poon RT, Ngan H, Lo CM, et al: Transarteria chemoembolization for inoperable hepatocellular carcinoma and postresection intrahepatic recurrence. J Surg Oncol 2000;73:109-114.

25 O'Suilleabhain CB, Poon RT, Yong JL, et al: Factors predictive of 5-year survival after transarterial chemoembolization for inoperable hepatocellular carcinoma. Br J Surg 2003;90:325-331.

26 Katyal S, Oliver JH, Peterson MS, et al: Prognostic significance of arterial phase CT for prediction of response to transcatheter arterial chemoembolization in unresectable hepatocellular carcinoma: a retrospective analysis. AJR Am J Roentgenol 2000;175:1665-1672.

27 Bronowicki JP, Vetter D, Dumas F, et al: Transcatheter oily chemoembolization for hepatocellular carcinoma. A 4-year study of 127 French patients. Cancer 1994;74:16-24.

28 Herber SC, Otto G, Schneider J, et al: Transarterial chemoembolization in patients not eligible for liver transplantation: single-center results. AJR Am J Roentgenol 2008;190:1035-1042.

29 Barone M, Ettorre GC, Ladisa R, et al: Transcatheter arterial chemoembolization (TACE) in treatment of hepatocellular carcinoma. Hepatogastroenterology 2003;50:183-187.

30 Llado L, Virgili J, Figueras J, et al: A prognostic index of the survival of patients with unresectable hepatocellular carcinoma after transcatheter arterial chemoembolization. Cancer 2000;88:50-57.

31 Chen CH, Hu FC, Huang GT, et al: Applicability of staging systems for patients with hepatocellular carcinoma is dependent on treatment method analysis of 2010 Taiwanese patients. Eur J Cancer 2009;45:1630-1639.

32 Hsu KF, Chu CH, Chan DC, et al: Superselective transarterial chemoembolization vs hepatic resection for resectable early-stage hepatocellular carcinoma in patients with Child-Pugh class a liver function. Eur J Radiol 2011;81:466-471.

33 Ho MC, Huang GT, Tsang YM, et al: Liver resection improves survival of patients with multiple hepatocellular carcinomas. Ann Surg Oncol 2009;16:848-855. 
34 Lewandowski RJ, Mulcahy MF, Kulik LM, et al: Chemoembolization for hepatocellular carcinoma: comprehensive imaging and survival analysis in a 172-patient cohort. Radiology 2010;255:955-965.

35 Salem R, Lewandowski RJ, Kulik L, et al: Radioembolization results in longer time-to-progression and reduced toxicity compared with chemoembolization in patients with hepatocellular carcinoma. Gastroenterology 2011;140:497-507.

36 Wang JH, Changchien CS, Hu TH, et al: The efficacy of treatment schedules according to Barcelona Clinic Liver Cancer staging for hepatocellular carcinoma - survival analysis of 3892 patients. Eur J Cancer 2008;44:1000-1006.

37 Farinati F, De Maria N, Marafin C, et al: Unresectable hepatocellular carcinoma in cirrhosis: survival, prognostic factors, and unexpected side effects after transcatheter arterial chemoembolization. Dig Dis Sci 1996:41:2332-2339.

38 Chen MS, Li JQ, Zhang YQ, et al: High-dose iodized oil transcatheter arterial chemoembolization for patients with large hepatocellular carcinoma. World J Gastroenterol 2002;8:74-78.

39 Huo T, Huang YH, Wu JC, et al: Comparison of transarterial chemoembolization and percutaneous acetic acid injection as the primary loco-regional therapy for unresectable hepatocellular carcinoma: a prospective survey. Aliment Pharmacol Ther 2004;19:1301-1308.

40 Nouso K, Ito Y, Kuwaki K, et al: Prognostic factors and treatment effects for hepatocellular carcinoma in child C cirrhosis. Br J Cancer 2008;98:1161-1165.

41 Lewandowski RJ, Kulik LM, Riaz A, et al: A comparative analysis of transarterial downstaging for hepatocellular carcinoma: chemoembolization versus radioembolization. Am J Transplant 2009;9: 1920-1928.

42 Luo J, Guo RP, Lai EC, et al: Transarterial chemoembolization for unresectable hepatocellular carcinoma with portal vein tumor thrombosis: a prospective comparative study. Ann Surg Oncol 2011; 18:413-420.

43 Kim KM, Kim JH, Park IS, et al: Reappraisal of repeated transarterial chemoembolization in the treatment of hepatocellular carcinoma with portal vein invasion. J Gastroenterol Hepatol 2009;24:806-814.

44 Wigmore SJ, Redhead DN, Thomson BN, et al: Postchemoembolisation syndrome - tumour necrosis or hepatocyte injury? Br J Cancer 2003;89: 1423-1427.

45 Chan A, Yuen MF, Hui CK, et al: A prospective study regarding the complications of transcatheter intraarterial lipiodol chemoembolization in patients with hepatocellular carcinoma. Cancer 2002; 94:1747-1752.

46 Castells A, Bruix J, Ayuso C, et al: Transarterial embolization for hepatocellular carcinoma. Antibiotic prophylaxis and clinical meaning of postembolization fever. J Hepatol 1995;22:410-415.

47 Chung JW, Park JH, Han JK, et al: Hepatic tumors: predisposing factors for complications of transcatheter oily chemoembolization. Radiology 1996;198:33-40.

48 Pietrosi G, Miraglia R, Luca A, et al: Arteria chemoembolization/embolization and early complications after hepatocellular carcinoma treatment: a safe standardized protocol in selected patients with child class A and B cirrhosis. J Vasc Interv Radiol 2009;20:896-902.

49 Kim HK, Chung YH, Song BC, et al: Ischemic bile duct injury as a serious complication after transarterial chemoembolization in patients with hepatocellular carcinoma. J Clin Gastroenterol 2001;32: 423-427.
50 Yu JS, Kim KW, Jeong MG, et al: Predisposing factors of bile duct injury after transcatheter arterial chemoembolization (TACE) for hepatic malignancy. Cardiovasc Intervent Radiol 2002;25:270-274.

51 Chen JH, Ho YJ, Shen WC: Asymptomatic arteriobiliary fistula after transarterial chemoembolization of metastatic liver tumors. Hepatogastroenterology 2001;48:842-843.

52 Leung TK, Lee CM, Chen HC: Anatomic and technical skill factor of gastroduodenal complication in post-transarterial embolization for hepatocellular carcinoma: a retrospective study of 280 cases. World J Gastroenterol 2005;11:1554-1557.

53 Shi M, Chen JA, Lin XJ, et al: Transarterial chemoembolization as initial treatment for unresectable hepatocellular carcinoma in southern China. World J Gastroenterol 2010;16:264-269.

54 Raoul JL, Sangro B, Forner A, et al: Evolving strategies for the management of intermediatestage hepatocellular carcinoma: available evidence and expert opinion on the use of transarterial chemoembolization. Cancer Treat Rev 2011;37: 212-220.

55 Hong K, Khwaja A, Liapi E, et al: New intra-arterial drug delivery system for the treatment of liver cancer: preclinical assessment in a rabbit model. Clin Cancer Res 2006;12:2563-2567.

56 Poon RT, Tso WK, Pang RW, et al: A phase I/II trial of chemoembolization for hepatocellular carcinoma using a novel intra-arterial drug-eluting bead. Clin Gastroenterol Hepatol 2007;5:1100-1108.

57 Varela M, Real MI, Burrel M, et al: Chemoembolization of hepatocellular carcinoma with drug eluting beads: efficacy and doxorubicin pharmacokinetics. J Hepatol 2007;46:474-481.

58 Reyes DK, Vossen JA, Kamel IR, et al: Singlecenter phase II trial of transarterial chemoembolization with drug-eluting beads for patients with unresectable hepatocellular carcinoma: initial experience in the United States. Cancer J 2009;15: 526-532.

59 Lammer J, Malagari K, Vogl T, et al: Prospective randomized study of doxorubicin-eluting-bead embolization in the treatment of hepatocellular carcinoma: results of the PRECISION V study. Cardiovasc Intervent Radiol 2010;33:41-52.

60 Grosso M, Vignali C, Quaretti P, et al: Transarterial chemoembolization for hepatocellular carcinoma with drug-eluting microspheres: preliminary results from an Italian multicentre study. Cardiovasc Intervent Radiol 2008;31:1141-1149.

61 Malagari K, Pomoni M, Moschouris H, et al: Chemoembolization with doxorubicin eluting beads for unresectable hepatocellular carcinoma: five-year survival analysis. Cardiovasc Intervent Radiol 2012;35:1119-1128.

62 Malagari K, Pomoni M, Kelekis A, et al: Prospective randomized comparison of chemoembolization with doxorubicin-eluting beads and bland embolization with BeadBlock for hepatocellular carcinoma. Cardiovasc Intervent Radiol 2010;33:541-551.

63 Burrel M, Reig M, Forner A, et al: Survival of patients with hepatocelllular carcinoma treated by transarterial chemoembolisation (TACE) using Drug Eluting Beads. Implications for clinical practice and trial design. J Hepatol 2012;56:1330-1335.

64 Li X, Feng GS, Zheng CS, Zhuo CK, Liu X: Expression of plasma vascular endothelial growth factor in patients with hepatocellular carcinoma and effect of transcatheter arterial chemoembolization therapy on plasma vascular endothelial growth factor level. World J Gastroenterol 2004;10:2878-2882.
65 Shim JH, Park JW, Kim JH, et al: Association between increment of serum VEGF level and prognosis after transcatheter arterial chemoembolization in hepatocellular carcinoma patients. Cancer Sci 2008;99:2037-2044.

66 Sergio A, Cristofori C, Cardin R, et al: Transcatheter arterial chemoembolization (TACE) in hepatocellular carcinoma (HCC): the role of angiogenesis and invasiveness. Am J Gastroenterol 2008; 103:914-921.

67 Strebel BM, Dufour JF: Combined approach to hepatocellular carcinoma: a new treatment concept for nonresectable disease. Expert Rev Anticancer Ther 2008;8:1743-1749.

68 www.clinicaltrials.gov/ct2/results?term $=$ hepatocellular + carcinoma + TACE + sorafenib.

69 Kudo M, Imanaka K, Chida N, et al: Phase III study of sorafenib after transarterial chemoembolisation in Japanese and Korean patients with unresectable hepatocellular carcinoma. Eur J Cancer 2011;47:2117-2127.

70 Park JW, Koh YH, Kim HB, et al: Phase II study of concurrent transarterial chemoembolization and sorafenib in patients with unresectable hepatocellular carcinoma. J Hepatol 2012;56:1336-1342.

71 Pawlik TM, Reyes DK, Cosgrove D, et al: Phase II trial of sorafenib combined with concurrent transarterial chemoembolization with drug-eluting beads for hepatocellular carcinoma. J Clin Oncol 2011;29: 3960-3967.

72 Lencioni R, Llovet JM, Han G, et al: Sorafenib or placebo in combination with transarterial chemoembolization (TACE) with doxorubicin-eluting beads (DEBDOX) for intermediate-stage hepatocellular carcinoma: phase II, randomized, doubleblind SPACE trial. J Clin Oncol 2012;30(suppl 4): LBA 154

73 Kennedy A, Nag S, Salem R, et al: Recommendations for radioembolization of hepatic malignancies using yttrium-90 micorsphere brachiterapy: a consensus panel report from the radioembolization brachyterapy oncology conssortium. Int J Radiat Oncol Biol Phys 2007;68:13-23.

74 Coldwell D, Sangro B, Wasan H, et al: General selection criteria of patients for radioembolization of liver tumors: an international working group report. Am J Clin Oncol 2011;34:337-341.

75 Lau W, Leung W, Ho S, et al: Treatment of hepatocellular carcinoma with intra-hepatic arterial yttrium-90 microspheres: a phase I and II study. Br J Cancer 1994;70:994-999.

76 Geschwind JF, Salem R, Carr BI, et al: Yttrium-90 microspheres for the treatment of hepatocellular carcinoma. Gastroenterology 2004;127:S194-205.

77 Salem R, Lewandowski RJ, Atassi B, et al: Treatment of unresectable hepatocellular carcinoma with use of $90 \mathrm{Y}$ microspheres (TheraSphere): safety, tumor response, and survival. J Vasc Interv Radiol 2005;16:1627-1639.

78 Sangro B, Bilbao JI, Boan J, et al: Radioembolization using 90Y-resin microspheres for patients with advanced hepatocellular carcinoma. Int J Radiat Oncol Biol Phys 2006;66:792-800.

79 Kulik LM, Atassi B, van Holsbeeck L, et al Yttrium-90 microspheres (TheraSphere) treatment of unresectable hepatocellular carcinoma: downstaging to resection, RFA and bridge to transplantation. J Surg Oncol 2006;94:572-586.

80 Kulik LM, Carr BI, Mulcahy MF, et al: Safety and efficacy of $90 \mathrm{Y}$ radiotherapy for hepatocellular carcinoma with and without portal vein thrombosis. Hepatology 2008;47:71-81. 
81 Iñarrairaegui M, Thurston KG, Bilbao JI, et al: Radioembolization with use of yttrium-90 resin microspheres in patients with hepatocellular carcinoma and portal vein thrombosis. J Vasc Interv Radiol 2010;21:1205-1212.

82 Iñarrairaegui M, Martinez-Cuesta A, Rodríguez M, et al: Analysis of prognostic factors after yttrium- 90 radioembolization of advanced hepatocellular carcinoma. Int J Radiat Oncol Biol Phys 2010;77: 1441-1448.

83 Salem R, Lewandowski RJ, Mulcahy MF, et al: Radioembolization for hepatocellular carcinoma using Yttrium-90 microspheres: a comprehensive report of long-term outcomes. Gastroenterology 2010;138:52-64.

84 Hilgard P, Hamami M, Fouly AE, et al: Radioembolization with yttrium-90 glass microspheres in hepatocellular carcinoma: European experience on safety and long-term survival. Hepatology 2010;52: 1741-1749.

85 Sangro B, Carpanese L, Cianni R; on behalf of the European Network on Radioembolization with Yttrium-90 Resin Microspheres (ENRY): Survival after Yttrium-90 resin microsphere radioembolization of hepatocellular carcinoma across Barcelona clinic liver cancer stages: a European evaluation. Hepatology 2011;54:868-878.

86 Mazzaferro V, Sposito C, Bhoori S, et al: Yttrium90 radioembolization for intermediate-advanced hepatocarcinoma: a phase II study. Hepatology 2012;DOI: 10.1002/hep.26014.

87 Jelic S, Sotiropoulos GC; ESMO Guidelines Working Group: Hepatocellular carcinoma: ESMO Clinical Practice Guidelines for diagnosis, treatment and follow-up. Ann Oncol 2010;21(suppl 5);v59-64.

88 Benson AB, Abrams TA, Ben-Josef E: NCCN clinical practice guidelines in oncology: hepatobiliary cancers. J Natl Compr Canc Netw 2009;7:350-391.

89 Riaz A, Kulik L, Lewandowski RJ, et al: Radiologicpathologic correlation of hepatocellular carcinoma treated with internal radiation using yttrium-90 microspheres. Hepatology 2009;49:1185-1193.
90 Heckman JT, Devera MB, Marsh JW, et al: Bridging locoregional therapy for hepatocellular carcinoma prior to liver transplantation. Ann Surg Oncol 2008;15:3169-3177.

91 Gaba RC, Lewandowski RJ, Kulik LM, et al: Radiation lobectomy: preliminary findings of hepatic volumetric response to lobar yttrium-90 radioembolization. Ann Surg Oncol 2009;16:1587-1596.

92 Iñarrairaegui M, Pardo F, Bilbao JI, et al: Response to radioembolization with yttrium-90 resin microspheres may allow surgical treatment with curative intent and prolonged survival in previously unresectable hepatocellular carcinoma. Eur J Surg Oncol 2012;38:594-601.

93 Carr BI, Kondragunta V, Buch SC, et al: Therapeutic equivalence in survival for hepatic arterial chemoembolization and yttrium-90 microsphere treatments in unresectable hepatocellular carcinoma: a two cohort study. Cancer 2010;116: $1305-1314$.

94 Kooby DA, Egnatashvili V, Srinivasan S, et al: Comparison of yttrium-90 radioembolization and transcatheter arterial chemoembolization for the treatment of unresectable hepatocellular carcinoma. J Vasc Interv Radiol 2010;21:224-230.

95 Moreno-Luna LE, Yang JD, Sanchez W, et al: Efficacy and safety of transarterial radioembolization versus chemoembolization in patients with hepatocellular carcinoma. Cardiovasc Intervent Radiol 2012;DOI: 10.1007/s00270-012-0481-2.

96 D'Avola D, Inarrairaegui M, Bilbao JI, et al: A retrospective comparative analysis of the effect of Y90-radioembolization on the survival of patients with unresectable hepatocellular carcinoma. Hepatogastroenterology 2009;56:1683-1688.

97 Bruix J, Raoul JL, Sherman M, et al: Efficacy and safety of sorafenib in patients with advanced hepatocellular carcinoma: subanalyses of a phase III trial. J Hepatol 2012;57:821-829.

98 Sato K, Lewandowski RJ, Bui JT, et al: Treatment of unresectable primary and metastatic liver cancer with yttrium-90 microspheres (TheraSphere): assessment of hepatic arterial embolization. Cardiovasc Intervent Radiol 2006;29:522-529.
99 Bilbao JI, de Martino A, de Luis E, et al: Biocompatibility, inflammatory response, and recanalization characteristics of nonradioactive resin microspheres: histological findings. Cardiovasc Intervent Radiol 2009;32:727-736.

100 Cheng AL, Kang YK, Chen Z, et al: Efficacy and safety of sorafenib in patients in the Asia-Pacific region with advanced hepatocellular carcinoma: a phase III randomized, double-blind, placebo-controlled trial. Lancet Oncol 2009;10:25-34.

101 Woodall CE, Scoggins CR, Ellis SF, et al: Is selective internal radioembolization safe and effective for patients with inoperable hepatocellular carcinoma and venous thrombosis? J Am Coll Surg 2009;208:375-382.

102 Uchino K, Tateishi R, Shiina S, et al: Hepatocellular carcinoma with extrahepatic metastasis: clinical features and prognostic factors. Cancer 2011;117:4475-4483.

103 Leung TW, Lau WY, Ho SK, et al: Radiation pneumonitis after selective internal radiation treatment with intraarterial 90yttrium-microspheres for inoperable hepatic tumors. Int $\mathrm{J}$ Radiat Oncol Biol Phys 1995;33:919-924.

104 Carr BI: Hepatic arterial 90Yttrium glass microspheres (Therasphere) for unresectable hepatocellular carcinoma: interim safety and survival data on 65 patients. Liver Transpl 2004;10:S107-S110.

105 Carretero C, Munoz-Navas M, Betes M, et al: Gastroduodenal injury after radioembolization of hepatic tumors. Am J Gastroenterol 2007;102: 1216-1220.

106 Riaz A, Gates VL, Atassi B, et al: Radiation segmentectomy: a novel approach to increase safety and efficacy of radioembolization. Int $\mathrm{J}$ Radiat Oncol Biol Phys 2011;79:163-171.

107 Sangro B, Gil-Alzugaray B, Rodriguez J, et al: Liver disease induced by radioembolization of liver tumors. Cancer 2008;112:1538-1546.

108 Gil-Alzugaray B, Chopitea A, Iñarrairaegui M, et al: Prognostic factors and prevention of radioembolization-induced liver disease. Hepatology 2012;DOI: 10.1002/hep.26191. 